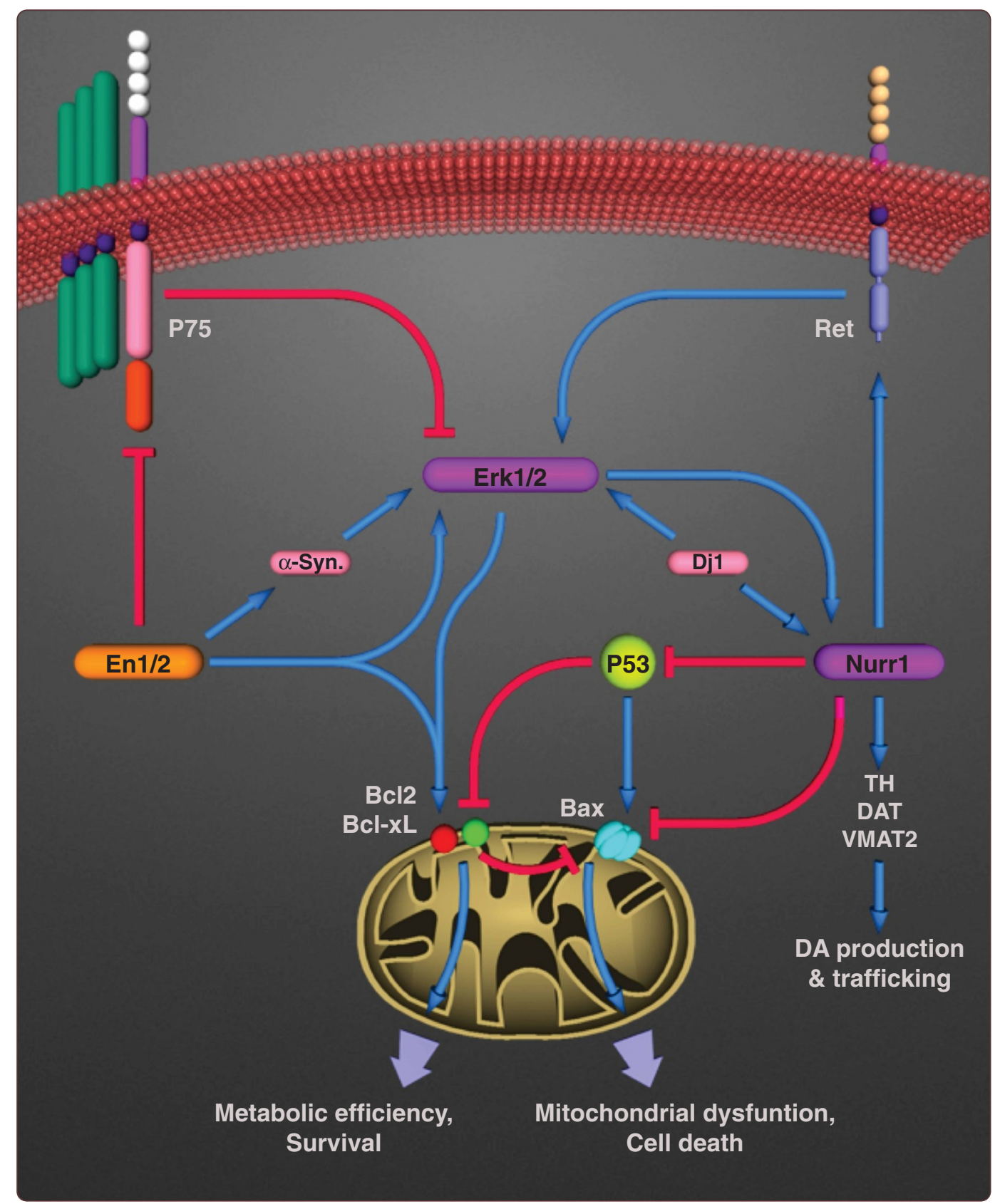

The lifelong maintenance of mesencephalic
dopaminergic neurons by Nurr1 and engrailed

Alavian et al. 


\title{
The lifelong maintenance of mesencephalic dopaminergic neurons by Nurr1 and engrailed
}

\author{
Kambiz N Alavian ${ }^{1,2,3^{*}}$, Sharmin Jeddi ${ }^{2}$ Sahar I Naghipour ${ }^{2}$, Pegah Nabili ${ }^{1}$, Pawel Licznerski ${ }^{3}$ and Travis S Tierney $^{4}$
}

\begin{abstract}
Specific vulnerability and degeneration of the dopaminergic neurons in the substantia nigra pars compacta of the midbrain is the pathological hallmark of Parkinson's disease. A number of transcription factors regulate the birth and development of this set of neurons and some remain constitutively expressed throughout life. These maintenance transcription factors are closely associated with essential neurophysiological functions and are required ultimately for the long-term survival of the midbrain dopaminergic neurons. The current review describes the role of two such factors, Nurr1 and engrailed, in differentiation, maturation, and in normal physiological functions including acquisition of neurotransmitter identity. The review will also elucidate the relationship of these factors with life, vulnerability, degeneration and death of mesencephalic dopaminergic neurons in the context of Parkinson's disease.
\end{abstract}

\section{Review Introduction}

Parkinson's disease (PD) is the second most prevalent neurodegenerative disorder, affecting $1-2 \%$ of the population over 65 and 3-5\% of the people over 85 [1]. The disease initially manifests with the cardinal motor symptoms of rest tremor, bradykinesia, rigidity, and postural instability. Over time non-motor symptoms such as depression, constipation, pain, genitourinary problems, and sleep disorders $[1,2]$ become prominent. The main pathological feature of PD is the degeneration of dopaminergic neurons in the substantia nigra pars compacta (SNpc). The other nearby mesencephalic dopaminergic (mesDA) neuronal populations within the ventral tegmental area (VTA) and retrorubral field (RRF) are less susceptible to degeneration and remain relatively unaffected during the course of the disease $[3,4]$.

A wide variety of animal models have been developed to study the pathological outcomes of cell death in the ventral midbrain and to explore potential therapeutic targets that can stabilize or remedy the condition [5,6]. In recent years, characterization of differential gene expression

\footnotetext{
* Correspondence: k.alavian@imperial.ac.uk

'Division of Brain Sciences, Department of Medicine, Imperial College, E508, Burlington Danes, Hammersmith Hospital, DuCane Road, London W12 ONN, UK

${ }^{2}$ The Bahá'í Institute for Higher Education (BIHE), Tehran, Iran

Full list of author information is available at the end of the article
}

profiles between the two main mesDA neuronal populations, VTA and SNpc, has been used to probe the question of relative susceptibility of neurons to environmental and genetic vulnerability [7]. Another approach to understand this susceptibility has been the study of the developmental cues that contribute directly or indirectly to differentiation of these phenotypes [8].

Based on these studies, we postulate that these neurons perpetually remain in a developmental state that is vulnerable to neurodegeneration because the critical period for naturally-occurring neuron death that occurs for most populations of neurons never completely closes for these unique cells in the ventral midbrain. This inherent vulnerability of mesDA neurons is a consequence of the unique expression profile of these cells which is controlled by a cascade of developmental transcription factors that are not only required for defining the regional identity of the midbrain and specification of mesDA neurons but also for the long-term survival and maintenance and normal physiological function. Several gain and loss of function studies in transgenic and mutant animals have demonstrated a strong connection between developmental factors and essential neuronal functions such as axon guidance, regulation of survival and cell death, defining the neurotransmitter phenotype, neuronal excitability and plasticity [8]. These studies have also established that the insufficiency in certain key transcription factors can lead to 
a neurodegenerative phenotype and subsequently to PD-like symptoms [9-12].

In this review we will discuss two transcription factors, engrailed and Nurr1, that are necessary for regulation of key events in the development of mesencephalic dopaminergic neurons as well as their survival and maintenance throughout life. In our discussion, we will highlight the role of these factors as key transcriptional regulators of differentiation, maturation and survival of mesDA neurons, the contribution of each factor to the normal physiological functions in postnatal mesDA neurons, as well as their possible connection with the vulnerability of neurons and etiology of Parkinson's disease.

\section{Nurr1}

Orphan nuclear receptor Nurr1 (nuclear receptor subfamily 4, group A, member 2; NR4A2) is a member of the steroid/thyroid hormone nuclear receptor and is related to a family of factors that modulate transcription in response to small lipophilic molecules. The transcriptional activity of these factors is regulated through the interaction of the ligand with the carboxy terminal ligand-binding domain of specific nuclear receptors [13]. Nurr1 transcription factor is encoded by an immediate early gene and is predominantly expressed in the brain $[14,15]$. Structurally, Nurr1 consists of a DNA binding domain, a ligand binding domain and two transcription activation function domains at the $\mathrm{N}$ - and C-termini (AF1 and AF2, respectively) [16,17]. The DNA binding domain of Nurr1 is highly conserved among the nuclear receptor family members and is comprised of two zinc finger modules. This domain is known to activate transcription through binding to an NGFI-B response element (NBRE) [18]. Nurr1 lacks a classical binding site for coactivators and the tight packing of side chains from hydrophobic residues in the ligand-binding domain prevents the molecule from having a ligand-binding cavity. The constitutive transcriptional activity of Nurr1, therefore, can be attributed to the canonical protein fold resembling the agonist-bound, transcriptionally active, ligand binding domains in nuclear receptors [19]. Nurr1 also activates transcription through heterodimerization with the retionid X receptor (RXR) and in response to the RXR ligands [20,21]. The AF1 and AF2 domains are also involved in co-factor recruitment and contribute to the constitutive transcriptional activation of Nurr1 [16,22].

In mice, the expression of Nurr1 can first be detected on embryonic day 10 (E10) in the ventral midbrain. Although the expression of the gene is reduced in the postnatal animals, it continues throughout life and has been shown to regulate several aspects of postmitotic development $[10,23,24]$. The role of Nurr1 in the survival and differentiation of mesDA neurons was initially discovered through mouse knockout studies, demonstrating loss of immunoreactivity for the rate-limiting enzyme in production of dopamine, tyrosine hydroxylase, in the mesDA neurons from Nurr1 knockout animals [25]. Later on further studies established that the neuroepithelial cells, that give rise to mesDA neurons, ventralize normally and differentiate into neurons. For example, they express mesDA neuron specific markers such as Pitx3, Ahd2 and engrailed $1 / 2$ and establish nigrostriatal axonal projections, but lack their dopaminergic phenotype [26-28]. Further examination of the transcriptional role of Nurr1 demonstrated that it is an upstream regulator of genes involved in the synthesis, packaging, transport and reuptake of dopamine [29,30]. For example, Nurr1 has been shown to induce the expression of tyrosine hydroxylase (TH) by directly transactivating the promoter of $\mathrm{TH}$ [31]. Regulation of the dopamine transporter (DAT) gene is another key function of Nurr1 in determining the neurotransmitter phenotype of mesDA neurons. This effect of Nurr1 seems to be independent of its classic heterodimerization partner, retinoid $\mathrm{X}$ receptor. The expression of $\mathrm{TH}$ and DAT is regulated by the high affinity binding of Nurr1 to an extended half-hormone response element, NGF1-B responsive element (NBRE), in their 5 '-untranslated regions $[32,33]$. Finally, other studies have shown that Nurr1 is involved in conversion of L-DOPA to DA and packaging of DA into synaptic vesicles by regulating the expression of aromatic L-amino acid decarboxylase (AADC) and vesicular monoamine transporter-2 (VMAT2), respectively [30].

In addition to transcriptional regulation of the genes involved in dopamine production and trafficking, Nurr1 is also a key convert factor in several survival and maintenance pathways. Nurr1 regulates the rearranged in transfection (Ret) gene from the earliest stages in embryonic development. Ret tyrosine kinase is the high-affinity ligand-binding component of the glial cell line derived neurotrophic factor (GDNF) receptor complex that is attached to the cell surface via a glycosyl phosphatidylinositol anchor [34]. GDNF has been shown to protect mesDA neurons against the developmental waves of apoptosis, neurotoxic insults and cell death [35-38]. Upon GDNF binding, autophosphorylation of the tyrosine domains of Ret triggers activation of several pathways including PI3K, MAPK which are required for neuronal survival and neurite outgrowth [39]. Interestingly, one of the downstream phosphorylation targets of the GDNF signaling pathway is the cAMP response element binding (CREB) protein, which is known to directly regulate the expression of Nurr1 by binding to its promoter [40].

Homozygous Nurr1 knockout pups die shortly after birth following degeneration of mesDA neurons [25-27]. However, Nurr1 haploinsufficient animals show no significant loss of mesDA neuron in number or motor function until late in life. The aging (>15 months old) Nurr1+/- 
mice have a decrease in the number of their nigral mesDA neurons and their locomotor activities, correlated with the reduced mesolimbic and mesocortical dopamine levels $[9,23]$. These animals also display increased vulnerability and cell death in response to neurotoxic insult $[9,41]$. The increased neuronal degeneration and death in these animals is likely to be due to mitochondrial dysfunction and the opening of the mitochondrial permeability transition pore [42]. Transcriptional regulation of the pro-and anti-apoptotic members of the Bcl-2 mitochondrial family of proteins and interaction with the
P53 tumor suppressor protein by Nurr1 are responsible for regulation of mitochondrial survival and death (Figure 1) [43]. The conditional knockout studies have further elucidated the role of Nurr1 in the survival and maintenance of mesDA neurons in the adult animals, showing that Nurr1-deficiency in maturing neurons results in a rapid loss of striatal dopamine, loss of mesDA specific markers and degeneration [10]. Taken together, these studies show that Nurr1 regulates both the phenotypic expression and survival of mesDA neurons in mice.

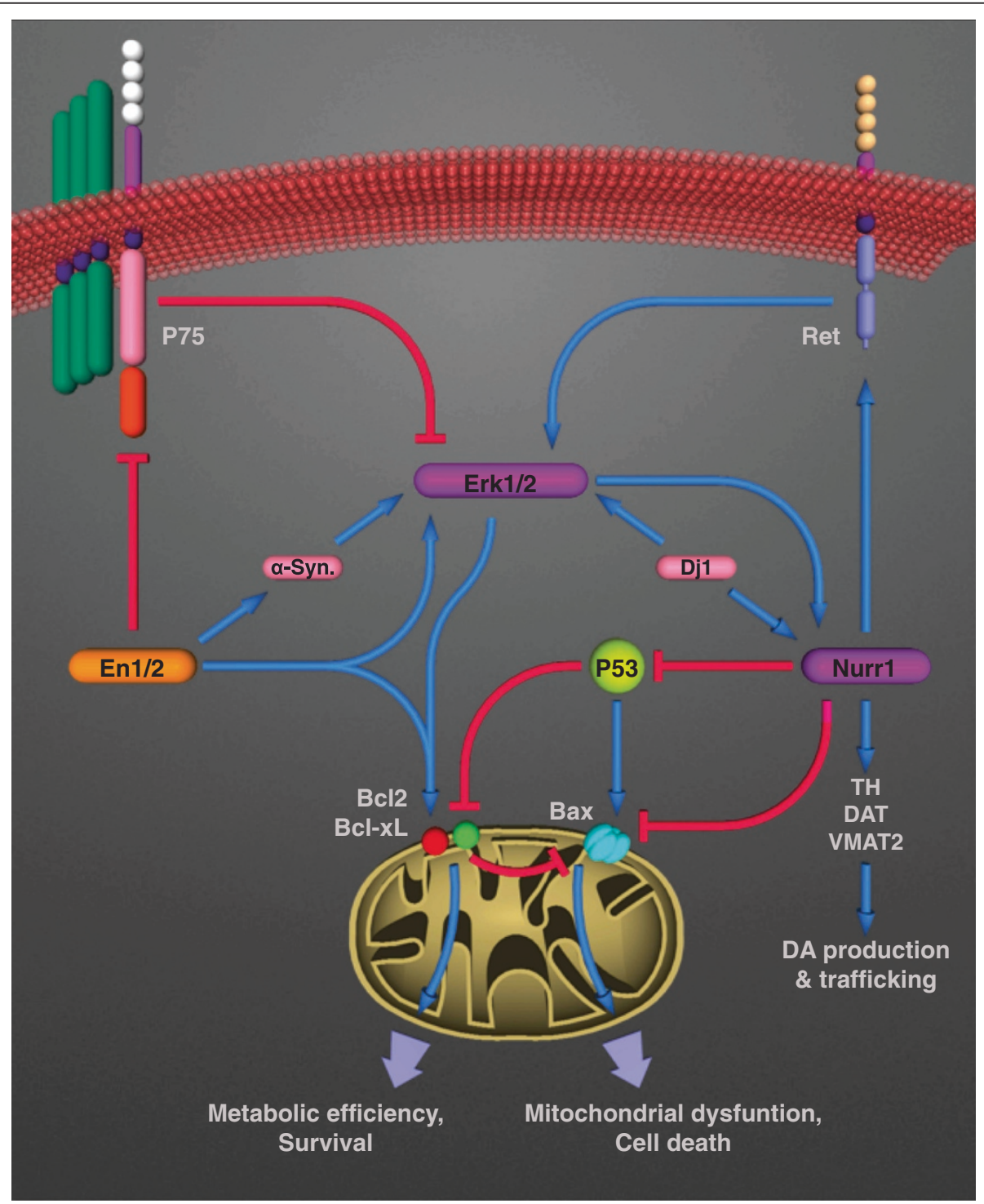

Figure 1 Signaling pathways involved in regulation of cellular survival and death by engrailed and Nurr1 in mesencephalic dopaminergic neurons. Transcriptional regulation of several survival/death-regulating genes including the pan-neurotrophin receptor P75 and protooncogene Ret, as well as modulation of downstream survival mechanisms, such as MAPK (Erk1/2) by engrailed and Nurr 1 leads to the long-term regulation of survival and death of mesDA neurons. Down-regulation of P75 expression by the engrailed genes results in disinhibition of Erk1/2, resulting in survival of mesDA neurons. The effect is similar to the Ret-mediated activation of Erk1/2 by Nurr1. The survival and degeneration pathways regulated by engrailed and Nurr1 converge on mitochondria and are mediated by the anti- and pro-apoptotic members of the Bcl-2 family, $\mathrm{BCl} 2, \mathrm{BCl}-\mathrm{XL}$ and $\mathrm{Bax}$ 
Given the neuoprotective role of Nurr1 demonstrated in animal models and its decreased or diminished expression levels in PD patients [44,45], a number of human genetic studies of the Nurr1 gene were undertaking to identify potential variants that may increase the risk of developing PD. Although the results from the studies within the past decade have failed to establish the mutations in Nurr1 as a cause or direct risk factor for PD, higher incidence of several mutations within the coding and non-coding regions of Nurr1 have been observed in familial and sporadic cases of the disease [46-49].

A number of these mutations have been associated with a marked decrease in the level of Nurr1 expression and subsequent reduction in the expression of $\mathrm{TH}$ [46]. The evidence from these studies accompanied by the results of the postmortem expression analysis in the PD patient brains suggest dysregulation of Nurr1 as a contributing factor to the onset and progression of neurodegeneration during the course of PD.

\section{The engrailed transcription factors}

The engrailed genes belong to the family of homeobox transcription factors, containing a highly conserved DNA binding, helix-turn-helix, homeodomain protein fold [50]. The morphological significance of the engrailed was first described in drosophila, where the autosomal mutant displays a long cleft of the thorax and irregular venation of the wings [51]. In addition to its early role in body segmentation, engrailed homologs in various annelid, mollusks, chordate and arthropod species has revealed a separate major function in neurogenesis [52-54]. Interestingly, homologs of engrailed are conserved among different phyla, to the degree that replacement of the mouse engrailed-1 gene by its paralog En2 or by the drosophila engrailed homolog will preserve its function in development and survival $[55,56]$.

The engrailed genes have two distinct functions during early and late development. The two paralogs of engrailed, En1 and En2, start their expression around E8 in mice in a broad region at the midbrain/hindbrain border, known as the isthmic organizer [57]. During this period, engrailed is involved in the induction of mesDA neurons by maintaining expression of Fgf8 in this region [58-60]. En1/2 directly regulate the expression of Fgf8 through interaction with a DNA-binding intronic fragment on Fgf8 [61]. In En1/2 deficient embryos the domain of expression of Fgf8 in the isthmus is reduced and leads an incomplete induction of mesDA neurons in the midbrain. The specific expression of the engrailed genes in mesDA neurons starts after the neurons are induced and become postmitotic, between E11.5 and E14 in mice [62]. After this point, expression of both engrailed genes is required for continued survival of these neurons.
Mouse knockout studies have shown that there is a direct correlation between the dose of expression of engrailed and its survival effect in mesDA neurons. Mice lacking all four alleles of the two transcription factors (En1-/-;En2-/-) show the most severe phenotype. In these mice, the induction of dopaminergic neurons in the ventral midbrain is affected, the differentiated postmitotic mesDA neurons display significant developmental defects including a lack of axonal outgrowth and eventually die between E12 and E14, matching the timeframe of the expression of engrailed genes in wildtype mesDA neurons $[62,63]$. The postmitotic survival effect of En1 is more prominent than that of En2, since the mice lacking En2 show less severe phenotypes than the En1-/- animals. All En1-/- animals (regardless of the expression of En2) exhibit an abnormal distribution of dopaminergic neurons in ventral midbrain and die at birth. En1+/+;En2-/- mice, however, are viable and fertile and show no obvious deficiencies with regard to their dopaminergic neurons [62,64]. The most interesting phenotype among the engrailed-deficient animals is that of the mice heterozygous for En1 and homozygous null for En2 (En1+/-;En2-/-) where the development of mesDA neurons seems to be normal until just after birth when $70 \%$ of the neurons are lost within the first three 3 postnatal months. This specific nigral dopaminergic cell loss is accompanied by diminished dopamine levels and release within the dorsal striatum, leading to a marked decrease in locomotion, an increase in freezing episodes and weight loss.

Engrailed regulates development, survival and maintenance of mesDA neurons through the cooperative action of multiple molecular pathways. Cell death in absence of engrailed is mediated by at least two molecular pathways, involving the pan-neurotrophin receptor, P75NTR and the mitochondria. The increase in expression of the neurotrophin receptor P75 is a common phenomenon observed in neuronal injury and naturally-occurring neuron death [65]. Similarly, engrailed deficiency causes an increase in the expression of P75 resulting in downregulation of the mitogen activated protein kinase (MAPK) survival pathways and deactivation of the extracellular regulated kinases Erk1/2 [66]. A second survival mechanism regulated by the expression of the engrailed genes affects the mitochondria. Similar to the Nurr1 haploinsufficient cells, the mesDA neurons heterozygous for En1 (either in presence or absence of En2) are more prone to mitochondrial insult and cell death induced by inhibition of the complex-I of the electron transport chain than their wildtype counterparts [66]. The dose-dependent survival role of the engrailed genes against mitochondrial instability is suggestive of another link between engrailed and the etiology of PD, since mitochondrial dysfunction has been implicated as one of the 
most prominent molecular mechanisms in the pathoetiology of Parkinson's disease [66-69].

These studies on the engrailed knockout animals spurred a search for mutant genes in humans with Parkinson's disease. These studies have established a significant association between sporadic PD and single nucleotide polymorphisms (SNPs) in an intronic region of En1, on the 3' downstream region of En1 and the promoter region of En2 [70-72].

\section{Conclusions}

Degeneration of dopaminergic neurons in the substantia nigra pars compacta is pathological hallmark of PD that is responsible for most of the motor symptoms of the disease. The inherent vulnerability of this neuronal population, as a root cause for degeneration, is attributed to the distinct gene expression profile of mesDA neurons in this region, which sets them apart from the neighboring neurons in the ventral tegmental area [73-75]. There is ample evidence suggesting that this basic physiological feature (i.e. vulnerability to degeneration) of the neurons and the underlying specific gene expression profile are defined very early on during the time that the cells assume their positional identity, become postmitotic and express their dopaminergic phenotype, even before the onset of axonal outgrowth. Some of the most compelling and direct evidence in support of this argument comes from the studies on the mice lacking the homeodomain transcription factor Pitx3, where the development of the neurons is halted, resulting in cell death only in the substantia nigra around E12 [76]. The engrailed transcription factors and Nurr1 begin their expression in mesDA neurons during the same time and, to a large extent, define the molecular identity of these neurons throughout life.

Given the gene-dose-dependent loss of mesDA neurons in the engrailed deficient mice and the severe mesDAspecific defects in the Nurr1 knockout animals, it can be concluded that the main role of these two factors beyond this critical period (E12-E14 in mice) is to protect the nigral dopaminergic neurons by maintaining the survival cues that are most active during the developmental and early stages of the life of mesDA neurons. The insights into the transcriptional regulation of survival by these factors, therefore, may provide an insight into the core issue of the specific vulnerability of nigral dopaminergic neurons. In recent years, a number of studies have revealed some of the downstream transcriptional targets and survival mechanisms that converge at the level of mitochondria and downstream of growth factors $[66,67]$. The expression of engrailed genes indirectly determines the level of phosphorylation of two mitogen activated protein kinase (MAPK) family members, Erk1/2, which act as mediators of survival, proliferation and differentiation in response to growth factors [66]. Erk1/2 as well as the other member of the MAPK family, Erk5, are known to contribute to the expression of $\mathrm{TH}$, differentiation as well as survival of mesDA neurons by elevating the transcriptional activity of Nurr1 (Figure 1) [77,78]. Erk1/2 can also cause phosphorylation, nuclear localization and activation of Nurr1, which in turn affects the expression levels of tyrosine hydroxylase. This mechanism is related to the expression of the autosomal recessive early onset PD gene DJ-1 (Figure 1) [79].

En1/2 and Nurr1 expression also prevents mitochondrial impairment, a well described pathogenic phenomenon in Parkinson's disease, by inhibiting neurotoxic insult and the mitochondrial pathway of apoptosis, through regulation of the pro- and anti-apoptotic member of Bcl-2 family (Figure 1) $[43,66,80]$. This function of the two transcription factors is likely to prevent the cells from undergoing mitochondrial permeability transition, which occurs in response to death stimuli. While the opening of the mitochondrial permeability transition pore is generally considered an acute pathological phenomenon, under certain conditions such as metabolic stress, it is plausible that subtle changes in the mitochondrial membrane potential or uncoupling of the mitochondrial inner membrane would result in chronic neurodegeneration. This mechanism is more likely to be the target for the long-term protective effects of engrailed and Nurr1. The molecular nature of this protective function remains to be determined.

\section{Competing interests}

The authors declare that they have no competing interests.

\section{Authors' contributions}

KNA wrote the manuscript; SJ, SIN, PN, PL and TST critically read and revised the manuscript. All authors have read and approved the final manuscript.

\section{Author details}

${ }^{1}$ Division of Brain Sciences, Department of Medicine, Imperial College, E508, Burlington Danes, Hammersmith Hospital, DuCane Road, London W12 0NN UK. The Bahá'í Institute for Higher Education (BIHE), Tehran, Iran. ${ }^{3}$ Department of Internal Medicine, Endocrinology, Yale University, New Haven, CT, USA. ${ }^{4}$ Department of Neurosurgery, Brigham and Women's Hospital, Harvard Medical School, Boston, MA, USA.

Received: 31 December 2013 Accepted: 28 March 2014 Published: 1 April 2014

\section{References}

1. Fahn S: Description of Parkinson's disease as a clinical syndrome. Ann N Y Acad Sci 2003, 991:1-14

2. Chaudhuri KR, Healy DG, Schapira AH: Non-motor symptoms of Parkinson's disease: diagnosis and management. Lancet Neurol 2006, 5(3):235-245.

3. Hirsch E, Graybiel AM, Agid YA: Melanized dopaminergic neurons are differentially susceptible to degeneration in Parkinson's disease. Nature 1988, 334(6180):345-348.

4. Yamada T, McGeer PL, Baimbridge KG, McGeer EG: Relative sparing in Parkinson's disease of substantia nigra dopamine neurons containing calbindin-D28K. Brain Res 1990, 526(2):303-307.

5. Harvey BK, Wang Y, Hoffer BJ: Transgenic rodent models of Parkinson's disease. Acta Neurochir Supp/ 2008, 101:89-92. 
6. Terzioglu M, Galter D: Parkinson's disease: genetic versus toxin-induced rodent models. FEBS J 2008, 275(7):1384-1391.

7. Greene JG: Current status and future directions of gene expression profiling in Parkinson's disease. Neurobiol Dis 2012, 45(1):76-82.

8. Alavian $\mathrm{KN}$, Scholz C, Simon $\mathrm{HH}$ : Transcriptional regulation of mesencephalic dopaminergic neurons: the full circle of life and death. Mov Disord 2008, 23(3):319-328

9. Jiang C, Wan X, He Y, Pan T, Jankovic J, Le W: Age-dependent dopaminergic dysfunction in Nurr1 knockout mice. Exp Neurol 2005, 191(1):154-162.

10. Kadkhodaei B, Ito T, Joodmardi E, Mattsson B, Rouillard C, Carta M, Muramatsu S, Sumi-lchinose C, Nomura T, Metzger D, Chambon P, Lindqvist E, Larsson NG, Olson L, Bjorklund A, Ichinose H, Perlmann T: Nurr1 is required for maintenance of maturing and adult midbrain dopamine neurons. J Neurosci 2009, 29(50):15923-15932.

11. Kittappa R, Chang WW, Awatramani RB, McKay RD: The foxa2 gene controls the birth and spontaneous degeneration of dopamine neurons in old age. PLOS Biol 2007, 5(12):e325

12. Sgado P, Alberi L, Gherbassi D, Galasso SL, Ramakers GM, Alavian KN, Smidt MP, Dyck RH, Simon HH: Slow progressive degeneration of nigral dopaminergic neurons in postnatal Engrailed mutant mice. Proc Natl Acad Sci U S A 2006, 103(41):15242-15247.

13. Ribeiro RC, Kushner PJ, Baxter JD: The nuclear hormone receptor gene superfamily. Annu Rev Med 1995, 46:443-453.

14. Law SW, Conneely OM, DeMayo FJ, O'Malley BW: Identification of a new brain-specific transcription factor, NURR1. Mol Endocrinol 1992, 6(12):2129-2135.

15. Zetterstrom RH, Williams R, Perlmann T, Olson L: Cellular expression of the immediate early transcription factors Nurr1 and NGFI-B suggests a gene regulatory role in several brain regions including the nigrostriatal dopamine system. Brain Res Mol Brain Res 1996, 41(1-2):111-120.

16. Castro DS, Arvidsson M, Bondesson BM, Perlmann T: Activity of the Nurr1 carboxyl-terminal domain depends on cell type and integrity of the activation function 2. J Biol Chem 1999, 274(52):37483-37490.

17. Nordzell M, Aarnisalo P, Benoit G, Castro DS, Perlmann T: Defining an $\mathrm{N}$-terminal activation domain of the orphan nuclear receptor Nurr1. Biochem Biophys Res Commun 2004, 313(1):205-211.

18. Paulsen RF, Granas K, Johnsen $H$, Rolseth $V$, Sterri S: Three related brain nuclear receptors, NGFI-B, Nurr1, and NOR-1, as transcriptional activators. J Mol Neurosci 1995, 6(4):249-255.

19. Wang Z, Benoit G, Liu J, Prasad S, Aarnisalo P, Liu X, Xu H, Walker NP, Perlmann T: Structure and function of Nurr1 identifies a class of ligand-independent nuclear receptors. Nature 2003, 423(6939):555-560.

20. Aarnisalo P, Kim CH, Lee JW, Perlmann T: Defining requirements for heterodimerization between the retinoid $X$ receptor and the orphan nuclear receptor Nurr1. J Biol Chem 2002, 277(38):35118-35123.

21. Perlmann T, Wallen-Mackenzie A: Nurr1, an orphan nuclear receptor with essential functions in developing dopamine cells. Cell Tissue Res 2004, 318(1):45-52.

22. Flaig R, Greschik H, Peluso-lltis C, Moras D: Structural basis for the cell-specific activities of the NGFI-B and the Nurr1 ligand-binding domain. J Biol Chem 2005, 280(19):19250-19258.

23. Jankovic J, Chen S, Le WD: The role of Nurr1 in the development of dopaminergic neurons and Parkinson's disease. Prog Neurobiol 2005 77(1-2):128-138.

24. Luo $Y$ : The function and mechanisms of Nurr1 action in midbrain dopaminergic neurons, from development and maintenance to survival. Int Rev Neurobiol 2012, 102:1-22.

25. Zetterstrom RH, Solomin L, Jansson L, Hoffer BJ, Olson L, Perlmann T: Dopamine neuron agenesis in Nurr1-deficient mice. Science 1997, 276(5310):248-250.

26. Saucedo-Cardenas O, Quintana-Hau JD, Le WD, Smidt MP, Cox JJ, De Mayo F, Burbach JP, Conneely OM: Nurr1 is essential for the induction of the dopaminergic phenotype and the survival of ventral mesencephalic late dopaminergic precursor neurons. Proc Natl Acad Sci U S A 1998, 95(7):4013-4018.

27. Wallen A, Zetterstrom RH, Solomin L, Arvidsson M, Olson L, Perlmann T: Fate of mesencephalic AHD2-expressing dopamine progenitor cells in NURR1 mutant mice. Exp Cell Res 1999, 253(2):737-746.

28. Witta J, Baffi JS, Palkovits M, Mezey E, Castillo SO, Nikodem VM: Nigrostriatal innervation is preserved in Nurr1-null mice, although dopaminergic neuron precursors are arrested from terminal differentiation. Brain Res Mol Brain Res 2000, 84(1-2):67-78.

29. Flames N, Hobert O: Transcriptional control of the terminal fate of monoaminergic neurons. Annu Rev Neurosci 2011, 34:153-184.

30. Hermanson E, Joseph B, Castro D, Lindqvist E, Aarnisalo P, Wallen A, Benoit $G$, Hengerer B, Olson L, Perlmann T: Nurr1 regulates dopamine synthesis and storage in MN9D dopamine cells. Exp Cell Res 2003, 288(2):324-334.

31. Kim KS, Kim CH, Hwang DY, Seo H, Chung S, Hong SJ, Lim JK, Anderson T, Isacson O: Orphan nuclear receptor Nurr1 directly transactivates the promoter activity of the tyrosine hydroxylase gene in a cell-specific manner. J Neurochem 2003, 85(3):622-634

32. Sacchetti $P$, Brownschidle LA, Granneman JG, Bannon MJ: Characterization of the $5^{\prime}$-flanking region of the human dopamine transporter gene. Brain Res Mol Brain Res 1999, 74(1-2):167-174.

33. Sacchetti P, Mitchell TR, Granneman JG, Bannon MJ: Nurr1 enhances transcription of the human dopamine transporter gene through a novel mechanism. J Neurochem 2001, 76(5):1565-1572.

34. Baloh RH, Enomoto $\mathrm{H}$, Johnson EM Jr, Milbrandt J: The GDNF family ligands and receptors - implications for neural development. Curr Opin Neurobiol 2000, 10(1):103-110.

35. Burke RE: In GDNF as a candidate striatal target-derived neurotrophic factor for the development of substantia nigra dopamine neurons. 70th edition. Edited by Riederer P, Reichmann H, Youdim MBH, Gerlach M. Springer Vienna: Parkinson's Disease and Related Disorders; 2006:41-45.

36. Clarkson ED, Zawada WM, Freed CR: GDNF improves survival and reduces apoptosis in human embryonic dopaminergic neurons in vitro. Cell Tissue Res 1997, 289(2):207-210.

37. Clarkson ED, Zawada WM, Freed CR: GDNF reduces apoptosis in dopaminergic neurons in vitro. Neuroreport 1995, 7(1):145-149.

38. Tomac A, Lindqvist E, Lin LF, Ogren SO, Young D, Hoffer BJ, Olson L: Protection and repair of the nigrostriatal dopaminergic system by GDNF in vivo. Nature 1995, 373(6512):335-339.

39. Airaksinen MS, Saarma M: The gdnf family/signalling, biological functions and therapeutic value. Nat Rev Neurosci 2002, 3(5):383-394.

40. Barneda-Zahonero B, Servitja JM, Badiola N, Minano-Molina AJ, Fado R, Saura CA, Rodriguez-Alvarez J: Nurr1 protein is required for N-methyl-D-aspartic acid (NMDA) receptor-mediated neuronal survival. J Biol Chem 2012, 287(14):11351-11362.

41. Le W, Conneely OM, He Y, Jankovic J, Appel SH: Reduced Nurr1 expression increases the vulnerability of mesencephalic dopamine neurons to MPTP-induced injury. J Neurochem 1999, 73(5):2218-2221.

42. Imam SZ, Jankovic J, Ali SF, Skinner JT, Xie W, Conneely OM, Le WD: Nitric oxide mediates increased susceptibility to dopaminergic damage in Nurr1 heterozygous mice. FASEB J 2005, 19(11):1441-1450.

43. Zhang T, Wang P, Ren H, Fan J, Wang G: NGFI-B nuclear orphan receptor Nurr1 interacts with p53 and suppresses its transcriptional activity. Mol Cancer Res 2009, 7(8):1408-1415.

44. Le W, Pan T, Huang M, Xu P, Xie W, Zhu W, Zhang X, Deng H, Jankovic J: Decreased NURR1 gene expression in patients with Parkinson's disease. J Neurol Sci 2008, 273(1-2):29-33.

45. Liu H, Wei L, Tao Q, Deng H, Ming M, Xu P, Le W: Decreased NURR1 and PITX3 gene expression in Chinese patients with Parkinson's disease. Eur J Neurol 2012, 19(6):870-875.

46. Le WD, Xu P, Jankovic J, Jiang $H$, Appel SH, Smith RG, Vassilatis DK: Mutations in NR4A2 associated with familial Parkinson disease. Nat Genet 2003, 33(1):85-89.

47. Wu Y, Peng R, Chen W, Zhang J, Li T, Wang Y, Gou Y, Yuan G: Association of the polymorphisms in NURR1 gene with Parkinson's disease. Zhonghua Yi Xue Yi Chuan Xue Za Zhi 2008, 25(6):693-696.

48. Xu PY, Liang R, Jankovic J, Hunter C, Zeng YX, Ashizawa T, Lai D, Le WD: Association of homozygous $7048 \mathrm{G} 7049$ variant in the intron six of Nurr1 gene with Parkinson's disease. Neurology 2002, 58(6):881-884.

49. Zheng K, Heydari B, Simon DK: A common NURR1 polymorphism associated with Parkinson disease and diffuse Lewy body disease. Arch Neurol 2003, 60(5):722-725

50. Religa TL, Johnson CM, Vu DM, Brewer SH, Dyer RB, Fersht AR: The helix-turn-helix motif as an ultrafast independently folding domain: the pathway of folding of Engrailed homeodomain. Proc Natl Acad Sci U S A 2007, 104(22):9272-9277. 
51. Eker R: The recessive mutant engrailed in Drosophila melanogaster. Hereditas 1929, 12:217-222

52. Gibert JM: The evolution of engrailed genes after duplication and speciation events. Dev Genes Evol 2002, 212(7):307-318.

53. Patel NH, Martin-Blanco E, Coleman KG, Poole SJ, Ellis MC, Kornberg TB, Goodman CS: Expression of engrailed proteins in arthropods, annelids, and chordates. Cell 1989, 58(5):955-968.

54. Wedeen CJ, Weisblat DA: Segmental expression of an engrailed-class gene during early development and neurogenesis in an annelid. Development 1991, 113(3):805-814.

55. Hanks M, Wurst W, Anson-Cartwright $L$, Auerbach AB, Joyner AL: Rescue of the En-1 mutant phenotype by replacement of En-1 with En-2. Science 1995, 269(5224):679-682.

56. Hanks MC, Loomis CA, Harris E, Tong CX, Anson-Cartwright L, Auerbach A, Joyner A: Drosophila engrailed can substitute for mouse Engrailed1 function in mid-hindbrain, but not limb development. Development 1998, 125(22):4521-4530

57. Davis CA, Joyner AL: Expression patterns of the homeo box-containing genes En-1 and En-2 and the proto-oncogene int-1 diverge during mouse development. Genes Dev 1988, 2(12B):1736-1744.

58. Scholpp S, Lohs C, Brand M: Engrailed and Fgf8 act synergistically to maintain the boundary between diencephalon and mesencephalon. Development 2003, 130(20):4881-4893.

59. Shamim H, Mahmood R, Logan C, Doherty P, Lumsden A, Mason I: Sequential roles for Fgf4, En1 and Fgf8 in specification and regionalisation of the midbrain. Development 1999, 126(5):945-959.

60. Ye W, Shimamura K, Rubenstein JL, Hynes MA, Rosenthal A: FGF and Shh signals control dopaminergic and serotonergic cell fate in the anterior neural plate. Cell 1998, 93(5):755-766.

61. Gemel J, Jacobsen C, MacArthur CA: Fibroblast growth factor-8 expression is regulated by intronic engrailed and Pbx1-binding sites. $J$ Biol Chem 1999, 274(9):6020-6026.

62. Simon HH, Saueressig H, Wurst W, Goulding MD, O'Leary DD: Fate of midbrain dopaminergic neurons controlled by the engrailed genes. J Neurosci 2001, 21(9):3126-3134.

63. Alberi L, Sgado P, Simon HH: Engrailed genes are cell-autonomously required to prevent apoptosis in mesencephalic dopaminergic neurons. Development 2004, 131(13):3229-3236.

64. Simon HH, Thuret S, Alberi L: Midbrain dopaminergic neurons: control of their cell fate by the engrailed transcription factors. Cell Tissue Res 2004, 318(1):53-61.

65. Ibanez CF, Simi A: p75 neurotrophin receptor signaling in nervous system injury and degeneration: paradox and opportunity. Trends Neurosci 2012, 35(7):431-440.

66. Alavian KN, Sgado P, Alberi L, Subramaniam S, Simon HH: Elevated P75NTR expression causes death of engrailed-deficient midbrain dopaminergic neurons by Erk1/2 suppression. Neural Dev 2009, 4:11

67. Alvarez-Fischer D, Fuchs J, Castagner F, Stettler O, Massiani-Beaudoin O, Moya KL, Bouillot C, Oertel WH, Lombes A, Faigle W, Joshi RL, Hartmann A, Prochiantz A: Engrailed protects mouse midbrain dopaminergic neurons against mitochondrial complex I insults. Nat Neurosci 2011, 14(10):1260-1266.

68. Schapira AH: Mitochondria in the aetiology and pathogenesis of Parkinson's disease. Lancet Neurol 2008, 7(1):97-109.

69. Schapira AH: Mitochondrial dysfunction in Parkinson's disease. Cell Death Differ 2007, 14(7):1261-1266.

70. Fuchs J, Mueller JC, Lichtner P, Schulte C, Munz M, Berg D, Wullner U, Illig T, Sharma M, Gasser T: The transcription factor PITX3 is associated with sporadic Parkinson's disease. Neurobiol Aging 2009, 30(5):731-738

71. Haubenberger D, Reinthaler E, Mueller JC, Pirker W, Katzenschlager R, Froehlich R, Bruecke T, Daniel G, Auff E, Zimprich A: Association of transcription factor polymorphisms PITX3 and EN1 with Parkinson's disease. Neurobiol Aging 2011, 32(2):302-307.

72. Rissling I, Strauch K, Hoft C, Oertel WH, Moller JC: Haplotype analysis of the engrailed-2 gene in young-onset Parkinson's disease. Neurodegener Dis 2009, 6(3):102-105.

73. Chung $\mathrm{CY}$, Seo H, Sonntag KC, Brooks A, Lin L, Isacson O: Cell type-specific gene expression of midbrain dopaminergic neurons reveals molecules involved in their vulnerability and protection. Hum Mol Genet 2005, 14(13):1709-1725.
74. Greene JG, Dingledine R, Greenamyre JT: Gene expression profiling of rat midbrain dopamine neurons: implications for selective vulnerability in parkinsonism. Neurobiol Dis 2005, 18(1):19-31.

75. Grimm J, Mueller A, Hefti F, Rosenthal A: Molecular basis for catecholaminergic neuron diversity. Proc Natl Acad Sci U S A 2004, 101(38):13891-13896.

76. Smidt MP, Smits SM, Bouwmeester H, Hamers FP, Van Der Linden AJ, Hellemons AJ, Graw J, Burbach JP: Early developmental failure of substantia nigra dopamine neurons in mice lacking the homeodomain gene Pitx3. Development 2004, 131(5):1145-1155.

77. Jacobsen KX, MacDonald H, Lemonde S, Daigle M, Grimes DA, Bulman DE, Albert PR: A Nurr1 point mutant, implicated in Parkinson's disease, uncouples ERK1/2-dependent regulation of tyrosine hydroxylase transcription. Neurobiol Dis 2008, 29(1):117-122.

78. Sacchetti P, Carpentier R, Segard P, Olive-Cren C, Lefebvre P: Multiple signaling pathways regulate the transcriptional activity of the orphan nuclear receptor NURR1. Nucleic Acids Res 2006, 34(19):5515-5527.

79. Lu L, Sun X, Liu Y, Zhao H, Zhao S, Yang H: DJ-1 upregulates tyrosine hydroxylase gene expression by activating its transcriptional factor Nurr1 via the ERK1/2 pathway. Int J Biochem Cell Biol 2012, 44(1):65-71.

80. Lee MA, Lee HS, Cho KG, Jin BK, Sohn S, Lee YS, Ichinose H, Kim SU: Overexpression of midbrain-specific transcription factor Nurr1 modifies susceptibility of mouse neural stem cells to neurotoxins. Neurosci Lett 2002, 333(1):74-78.

doi:10.1186/1423-0127-21-27

Cite this article as: Alavian et al:: The lifelong maintenance of mesencephalic dopaminergic neurons by Nurr1 and engrailed. Journal of Biomedical Science 2014 21:27.

\section{Submit your next manuscript to BioMed Central and take full advantage of:}

- Convenient online submission

- Thorough peer review

- No space constraints or color figure charges

- Immediate publication on acceptance

- Inclusion in PubMed, CAS, Scopus and Google Scholar

- Research which is freely available for redistribution 